\title{
Predictors of 10-Year Stent-Related Adverse Outcomes after Coronary Drug-Eluting Stent Implantation: The Importance of Stent Size
}

\author{
Lars Kjøller-Hansen $^{a} \quad$ Henning Kelbæk ${ }^{a}$ Evald Høj Christiansen ${ }^{b}$ \\ Peter Riis Hansen $^{c}$ Thomas Engstrøm ${ }^{d}$ Anders Junker ${ }^{\mathrm{e}}$ Niels Bligaard $^{f}$ \\ Jørgen Lykke Jeppesen ${ }^{9}$ Anders Michael Galløe ${ }^{a}$

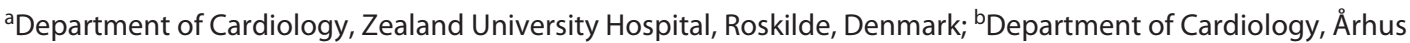 \\ University Hospital, Skejby, Aarhus, Denmark; 'Department of Cardiology, Copenhagen University Hospital, \\ Herlev-Gentofte, Copenhagen, Denmark; 'Department of Cardiology, Copenhagen University Hospital, \\ Righ hospitalet, Copenhagen, Denmark; 'Department of Cardiology, Odense University Hospital, Odense, Denmark; \\ fDepartment of Cardiology, Copenhagen University Hospital, Bispebjerg, Copenhagen, Denmark; ${ }^{9}$ Department of \\ Medicine, Amager Hvidovre Hospital Glostrup, University of Copenhagen, Copenhagen, Denmark
}

\section{Keywords}

Coronary artery disease $\cdot$ Predictors $\cdot$ PTCA/PCI $\cdot$ Restenosis

\begin{abstract}
Introduction: The predictors of stent treatment failure and their importance 10 years after treatment with drug-eluting stents (DESs) have not been reported in detail. Methods: Data were retrieved from the SORT-OUT II database encompassing 2,849 non-left main coronary lesions in 2,073 unselected all-comer patients treated with first-generation DES and followed clinically for 10 years. Stent treatment failure (STF) was defined as definite or probable stent thrombosis, target lesion revascularization (TLR), or $>70 \%$ restenosis left untreated. Target lesion failure (TLF) was defined as cardiac death, target vessel myocardial infarction, or TLR. Characteristics predicting higher hazard ratios (HRs) were identified by the multivariate Cox regression analysis. Results: A stent diameter $\leq 2.5$ versus $\geq 3.5 \mathrm{~mm}$ had STF 23.3 versus $11.8 \%$ and TLF 27.9 versus $18.8 \%$. Stent length $<20$ versus $>40 \mathrm{~mm}$ had STF 13.0 versus $29.0 \%$ and TLF 18.7 versus $34.6 \%$. In multivariate analysis, decreasing stent diameter (HR: 1.24 [3.0 $\mathrm{mm}$ ] to 2.12 [2.25 $\mathrm{mm}$ ], reference $\geq 3.5 \mathrm{~mm}$ ) and increasing stent length (HR: 1.15 [20-30 mm] to 2.07 [>40 mm], refer-
\end{abstract}

karger@karger.com

(C) 2021 S. Karger AG, Basel

www.karger.com/crd

Karger ${ }^{\prime}=$ ence $<20 \mathrm{~mm}$ ) predicted STF together with diabetes (HR: 1.31), previous revascularization (HR: 1.31), restenotic (HR: 2.25), bifurcation (HR: 1.45), and chronically occluded lesions (HR: 1.54). A predictive score (PS) was calculated for each lesion from the HRs for the predictors present. The 10-year rates of STF were $10 \%$ in lesions with a PS $\leq 1.5$ and $37 \%$ in those with PS $\geq 3.5$. Conclusions: Ten-year outcomes show large variations depending on the stent size and a few patient and lesion characteristics. The calculation of a PS from these unambiguous variables may be used to improve the risk estimate in individual lesions and patients.

(c) 2021 S. Karger AG, Basel

\section{Introduction}

After coronary artery stenting, the majority of patients will survive $>10$ years [1-3]. Therefore, knowledge of the very long-term outcomes and the predictors of outcomes after coronary artery stenting is important. The use of drugeluting stents (DESs) has improved the outcomes, but even with newer generation stents, stent-related adverse outcomes are an important issue. Randomized studies have found a relative reduction in stent-related adverse out- 
comes between 10 and 25\% with newer generation stents compared to first-generation DESs during up to 5-year follow-up. However, even in all-comer studies, the event rate varies $>100 \%$ between different studies for the same newgeneration DES stent type [4]. So what should you to tell the patient who asks "How long will my stent last?"

Target lesion failure (TLF) defined as cardiac death, target vessel myocardial infarction, and target lesion revascularization (TLR) is a standard outcome measure after coronary stenting. However, during a long-term follow-up, many cardiac deaths are not related to the initial stent treatment [5, 6]. Moreover, in cases where multiple lesions were originally treated with stents, uncertainty may exist as to which lesion or stent the patients' subsequent cardiac death should be ascribed.

Development of symptoms of restenosis and acute coronary syndromes often leads to repeat angiography and subsequent TLR, although in some cases, the patient or the lesion is deemed unsuitable for repeat revascularization. Such cases, along with stent thrombosis and TLR, might also be considered a failure of the respective stent treatment. Because of these limitations of TLF as an endpoint for long-term stent-related adverse outcomes, we found it more relevant to use an endpoint as stent treatment failure (STF) defined as definite or probable stent thrombosis, TLR, or restenosis $>70 \%$ on a clinically driven angiogram left untreated.

Data on long-term outcome derived from randomized studies and registries may be limited by inclusion of selected patients, loss to follow-up, and incomplete data on endpoints other than death. In the SORT-OUT II study, the patients included were representative of those undergoing PCI during the inclusion period, the 10-year follow-up was $99.2 \%$ complete, and all events were carefully adjudicated, as previously described $[1,7,8]$. So, to address some of the aforementioned issues and uncertainties to the long-term outcomes after coronary artery stenting, the main purpose of the present study was, using data from the SORT-OUT II, to demonstrate and quantitate the variation in outcomes depending on patients, lesion, and stent characteristics and to determine the predictors of the 10-year risk of stent treatment failure.

\section{Materials and Methods}

Between August 2004 and April 2006, a total of 2,131 all-comer patients in 5 Danish PCI centers were randomized in the SORTOUT II trial (NCT00388934) to treatment with a first-generation DES (the sirolimus-eluting Cypher stent [Cordis, Johnson and Johnson, Miami, FL, USA]) or the paclitaxel-eluting stent [Taxus,
Boston Scientific, Natick, MA, USA]) in 2,939 lesions. The study showed no differences in outcomes between the 2 stents up to 10 years $[1,7]$. Because left main stenting was only performed in special circumstances during the inclusion period and graft stenting is associated with a worse outcome, we prespecified to exclude left main and graft lesions. Furthermore, we excluded lesions in which a stent could not be implanted (balloon angioplasty only). In order to relate cardiac death, TLR, or target vessel myocardial infarction to a specific stent diameter and length, we prespecified that for the primary analysis on TLF, the study population was confined to 1,473 patients treated for only 1 lesion.

Clopidogrel $75 \mathrm{mg}$ daily was prescribed for 12 months and aspirin $75 \mathrm{mg}$ daily was prescribed indefinitely, and all patients were encouraged to participate in a rehabilitation program. Inclusion and exclusion criteria, patient baseline characteristics, and methods of event detection and adjudication of events by an independent event committee have been reported previously in addition to the main and 10-year follow-up results [1,7]. The study was approved by the Copenhagen County Ethics Committee (KA04085), and all patients gave written informed consent.

Stent thrombosis, target vessel myocardial infarction, and TLR were defined according to the Academic Research Consortium [9], with the exception that the angiographic stenosis grade and indication for TLR were determined by the treating physician, rather than an independent core lab. In addition, 148 patients included in a diabetes substudy had a prescheduled coronary angiogram performed after 9 months. All other angiograms performed during the follow-up were symptom-driven. Cardiac death was defined, as previously described [1], as any death that could not be clearly attributed to a noncardiac cause. Target lesions from the index PCI were reviewed and classified by 2 authors (A.M.G. and N.B.), as previously described [7]. Angiograms from clinical events were collected and reviewed by the event committee in cases of ambiguity. Endpoints were censored for patient's emigration and death. Frequencies of endpoints are presented as Kaplan-Meier estimates. A comparison of frequencies between groups was done using log-rank tests and the calculation of relative risks. We used SPSS v.21 for statistical calculations.

All patient, lesion, and stent characteristics available in the study database were used to perform a multivariate Cox proportional hazard model with hazard ratios (HRs) for STF. For missing values (up to $6 \%$ ), conditions not present were imputed. Other data were complete. Nominal stent diameters were used for the analysis. Stent diameters ranged from 2.25 to $4.0 \mathrm{~mm}$. Because few patients had 4.0$\mathrm{mm}$ stents implanted and this diameter was available only for the Taxus stent, results for the 3.5- and 4.0-mm-diameter stents were merged. In lesions treated with $>1$ stent, the smallest stent diameter and the sum of stent lengths (total stent length) were used. Predictor variables showing a relative risk $<0.80$ or $>1.25$ or a $p$ value $<0.05$ (from Kaplan-Meier estimates and log-rank test) were entered into the Cox regression multivariate model and kept in the model if the HR was $<0.80$ or $>1.25$ or $p$ value $<0.05$ and the log-likelihood test $\left(\chi^{2}\right)$ improved. We performed both forward and backward stepwise analyses. Proportional hazard assumptions were assessed by log minus log plots and in case of ambiguity by determining the size and significance of the coefficient of a time-dependent covariate (timeand $\log$ time $\times$ predictor variable of variable of interest). A predictive score (PS) was calculated for each lesion by multiplying the hazard ratios for each predictor variable present in the lesion. The expected STF rate was calculated as the mean PS $\times$ baseline hazard. 
Table 1. Stent treatment failure and components according to stent diameter and stent length

\begin{tabular}{|c|c|c|c|c|c|c|}
\hline \multicolumn{7}{|l|}{ Stent diameter, $\mathrm{mm}$} \\
\hline$\geq 3.5(n=846)$ & $11.8(92)$ & Reference & & $4.8(35)$ & $10.8(84)$ & $0.3(2)$ \\
\hline $3.0(n=996)$ & $15.0(133)$ & 1.27 & 0.081 & $6.8(60)$ & $13.4(119)$ & $1.0(8)$ \\
\hline $2.25(n=261)$ & $24.7(58)$ & 2.09 & $<0.001$ & $6.8(16)$ & $17.3(41)$ & $7.4(15)$ \\
\hline \multicolumn{7}{|l|}{ Stent length, mm } \\
\hline$<20(n=1,659)$ & $13.6(207)$ & Reference & & $5.2(77)$ & $11.1(170)$ & $1.7(24)$ \\
\hline $20-30(n=661)$ & $17.2(105)$ & 1.26 & 0.035 & $5.9(34)$ & $15.3(94)$ & $0.9(5)$ \\
\hline $31-40(n=272)$ & $21.6(50)$ & 1.59 & 0.005 & $9.6(22)$ & $18.3(42)$ & $1.9(4)$ \\
\hline$>40(n=257)$ & $29.0(68)$ & 2.13 & $<0.001$ & $12.0(28)$ & $26.3(62)$ & $3.6(6)$ \\
\hline
\end{tabular}

Percentages are Kaplan-Meier estimates, and numbers in brackets. All stent thromboses were definite or target vessel myocardial infarction except in 3 persons/lesions with sudden unexplained death within 30 days. STF, stent treatment failure; TLR, target lesion revascularization.

Table 2. Target lesion failure and components according to stent diameter and stent length

\begin{tabular}{|c|c|c|c|c|c|c|}
\hline \multicolumn{7}{|l|}{ Stent diameter } \\
\hline$\geq 3.5 \mathrm{~mm}(n=462)$ & $18.8(80)$ & & & $7.7(33)$ & $6.0(24)$ & $11.5(47)$ \\
\hline $3.0 \mathrm{~mm}(n=562)$ & $23.7(122)$ & 1.27 & 0.08 & $10.0(51)$ & $7.3(36)$ & $15.1(77)$ \\
\hline $2.75 \mathrm{~mm}(n=76)$ & $25.6(18)$ & 1.37 & 0.14 & $11.7(8)$ & $5.7(4)$ & $16.5(11)$ \\
\hline $2.5 \mathrm{~mm}(n=270)$ & $27.8(72)$ & 1.49 & 0.001 & $10.3(26)$ & $9.2(23)$ & $19.4(49)$ \\
\hline \multicolumn{7}{|l|}{ Stent length } \\
\hline$<20 \mathrm{~mm}(n=814)$ & $18.7(141)$ & & & $8.6(64)$ & $4.9(40)$ & $11.2(81)$ \\
\hline $20-30 \mathrm{~mm}(n=344)$ & $25.5(83)$ & 1.36 & 0.009 & $9.6(31)$ & $6.1(19)$ & $17.0(54)$ \\
\hline $31-40 \mathrm{~mm}(n=164)$ & $30.7(45)$ & 1.64 & 0.01 & $13.0(19)$ & $11.2(15)$ & $19.7(27)$ \\
\hline$>40 \mathrm{~mm}(n=151)$ & $34.6(49)$ & 1.85 & $<0.001$ & $10.1(14)$ & $14.5(20)$ & $27.7(38)$ \\
\hline
\end{tabular}

Percentages are Kaplan-Meier estimates. Numbers in brackets. TLF, target lesion failure; MI, myocardial infarction; TLR, target lesion revascularization.

To evaluate whether the predicted risk of STF increased incrementally when more lesions were treated in the same patient, we calculated the ratio of the mean PS per patient in the groups treated for multiple lesions and the mean PS in the single-lesion group. This ratio was then compared to the observed ratio of the total number of STF per number of patients in the 2 groups.

\section{Results}

We excluded 82 left main, graft, and balloon-only treated lesions and 8 lesions where information on stent size was unavailable. Accordingly, 2,849 lesions in 2,073 patients form the basis for the present study. Baseline patient and lesion characteristics according to stent diameter and stent length are presented in online suppl. Tables S1 and S2 (see www.karger.com/ doi/10.1159/000517614 for all online suppl. material).

The 10-year rates of STF and TLF and relative risks according to stent diameters and lengths are presented in Tables 1 and 2 and in Figure 1. For both composite endpoints and for their individual components, larger stent diameters and shorter stent lengths were associated with better outcomes. For treatment with a stent diameter of $\geq 3.0 \mathrm{~mm}$ and a stent length of $\leq 30 \mathrm{~mm}$, the 10 -year rate 


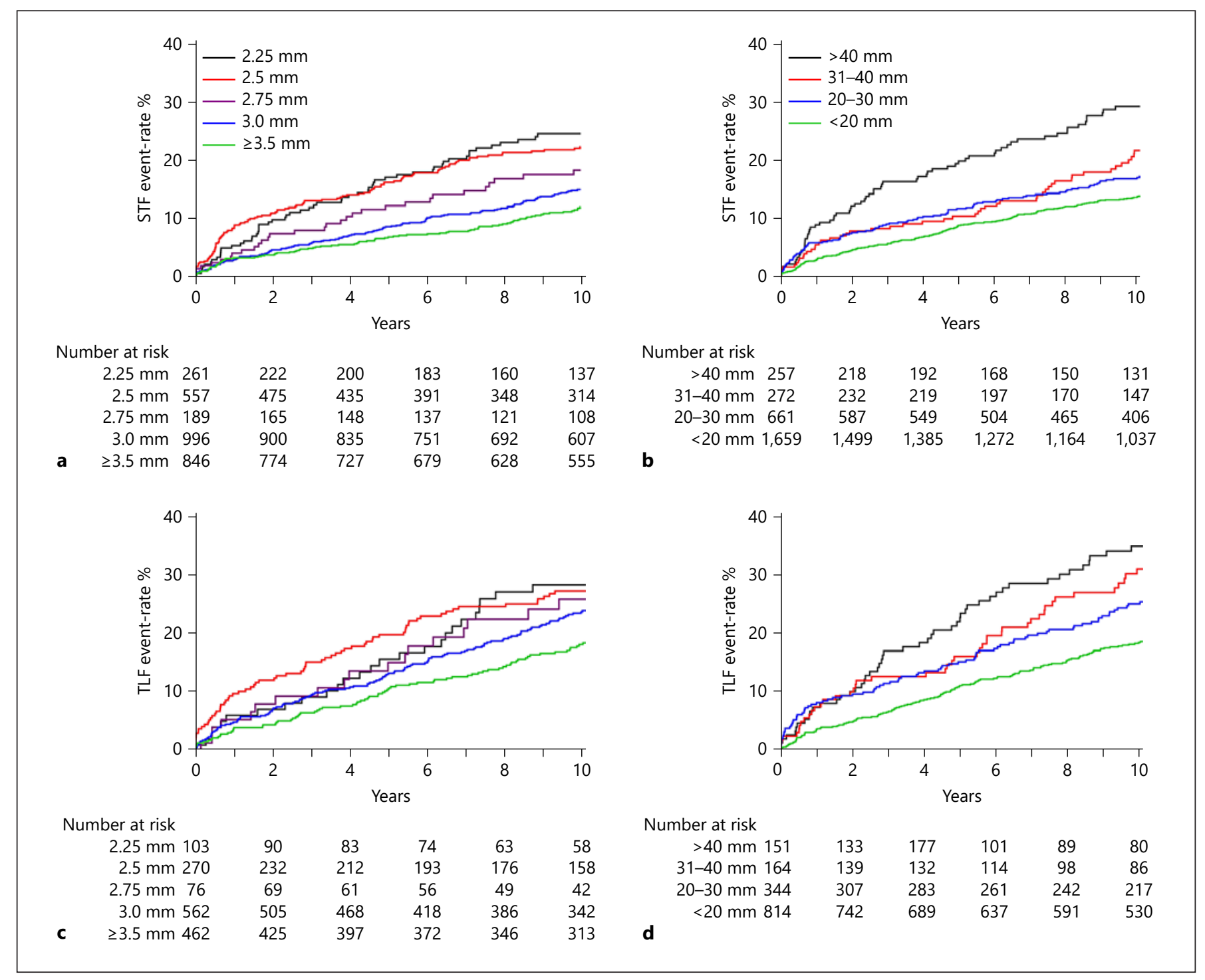

Fig. 1. a Ten-year stent treatment failure according to the stent diameter. STF: Definite or probable stent thrombosis, target lesion revascularization, or restenosis $>70 \%$ left untreated. $\mathbf{b}$ Ten-year stent treatment failure according to the stent length. c Ten-year target lesion failure according to the stent diameter. TLF: Cardiac death, target vessel myocardial infarction, or target lesion revascularization. $\mathbf{d}$ Ten-year target lesion failure according to the stent length. STF, stent treatment failure; TLF, target lesion failure.

of STF was $11.8 \%$ ( 171 in 1,544 lesions), with $3.1 \%$ the first year and $0.9 \%$ per year hereafter, TLR rates were 5.7 and $9.7 \%$ at 5 and 10 years, respectively, and TLF was $18.5 \%$ (148 in 836 patients), with $4.0 \%$ within the first year and $1.5 \%$ per year hereafter. In comparison, for lesions treated with a $2.25-\mathrm{mm}$-diameter stent and $>40 \mathrm{~mm}$ stent length, the 10 -year rate of STF (and TLR) was $48.3 \%$, with $19.2 \%$ the first year and on average $3.2 \%$ per year hereafter. The TLF rate was $59.0 \%$, with $22.9 \%$ within the first year and on average $4.0 \%$ per year hereafter. The neg- ative association of smaller diameter and longer stent length on the risk of STF and TLF was consistent by multivariate analysis (Table 3), and for events occurring later than 1 and 5 years, hazard rates were also higher with smaller diameter and longer stent length (online suppl. Tables S3 and S4).

Better outcomes for larger stent diameters were observed in all coronary segments and for shorter stent lengths in all 3 main coronary artery territories. Restenoses left untreated were also considerably more frequent in 
Table 3. Predictors of stent treatment failures determined by the multivariate Cox regression analysis

\begin{tabular}{llc}
\hline & HR $(95 \% \mathrm{CI})$ & $p$ value \\
\hline $\begin{array}{llc}\text { Stent diameter } \\
\quad 3.5 \mathrm{~mm}\end{array}$ & & \\
$\quad$ Reference & - \\
$\quad 2.0 \mathrm{~mm}$ & $1.24(0.95-1.62)$ & 0.12 \\
$\quad 1.5 \mathrm{~mm}$ & $1.54(1.02-2.32)$ & 0.041 \\
$\quad 2.5 \mathrm{~mm}$ & $2.00(1.52-2.54)$ & $<0.001$ \\
$\quad$ Stent length & $2.12(1.52-2.64)$ & $<0.001$ \\
$\quad$ & & \\
$\quad$ 20 mm & Reference & - \\
$\quad 31-40 \mathrm{~mm}$ & $1.15(0.91-1.46)$ & 0.25 \\
$\quad$ >40 mm & $1.41(1.03-1.93)$ & 0.03 \\
Restenotic lesion & $2.07(1.57-2.74)$ & $<0.001$ \\
Chronic total occlusion & $2.25(1.47-3.43)$ & $<0.001$ \\
Bifurcation lesion & $1.54(0.94-2.51)$ & 0.088 \\
Previous revascularization & $1.45(1.09-1.94)$ & 0.012 \\
Diabetes mellitus & $1.31(1.03-1.67)$ & 0.026 \\
Male gender & $1.31(1.05-1.65)$ & 0.018 \\
Age, per year* & $1.27(0.99-1.63)$ & 0.057 \\
\hline
\end{tabular}

HR, hazard ratio. * Range 31-94 years. HR was similar if 5 years' intervals (HR 0.90) or 10 years' intervals (HR 0.80) were used.

small diameter stents than in large diameter stents (or vessels) and in long stents than in shorter stents (or lesions) (Table 1).

The outcome for TLF in all 2,073 patients grouped according to the smallest stent diameter and the longest stent length implanted is presented in the supplemental materials (online suppl. Table S5) and shows a similar pattern as for the 1,473 patients treated for 1 lesion only. These data on all 2,073 patients have the drawback that for the 600 patients treated for $>1$ lesion, 24 TLR and 24 target vessel myocardial infarctions in fact were not related to the stent with the smallest diameter. Similarly, 26 TLR and 26 target vessel myocardial infarctions were not related to the longest stent length. Finally, with such a grouping, 60 cases of cardiac death are automatically ascribed the smallest stent diameter and the longest stent length, respectively.

The characteristics predicting an increased HR for STF by a multivariate Cox regression analysis are presented in Table 3. The distribution and relative risk of all tested characteristics by the univariate analysis are presented in the supplemental materials (online suppl. Table S6). Overlapping stents, SCAI-type, and ACC type C lesions were not independent predictors in the multivariate analyses. We found no statistical interactions between STF
Table 4. Ten-year stent treatment failure according to the predictive score

\begin{tabular}{lrlll}
\hline $\begin{array}{l}\text { Predictive } \\
\text { score }\end{array}$ & $N$ & $\begin{array}{l}\text { Mean PS } \\
\text { (SD) }\end{array}$ & $\begin{array}{l}\text { Observed } \\
\text { STF rate, } \\
\%\end{array}$ & $\begin{array}{l}\text { Expected } \\
\text { STF rate, } \\
\%\end{array}$ \\
\hline$\leq 1.5$ & 1,142 & $1.19(0.15)$ & 10.3 & 9.4 \\
$1.5-2.5$ & 988 & $1.93(0.27)$ & 16.0 & 16.1 \\
$>2.5-3.5$ & 456 & $2.88(0.26)$ & 23.2 & 24.2 \\
$\geq 3.5$ & 263 & $5.08(1.27)$ & 36.7 & 42.6
\end{tabular}

Calculated for each lesion by multiplying the hazard ratios for the predictors present in the lesion. Predictors: Stent diameter, stent length, diabetes mellitus, previous revascularization, treatment of restenotic lesion, chronic total occlusion, and bifurcation. Observed STF rate from Kaplan-Meier estimate. Expected STF rate calculated as mean PS $\times$ baseline hazard $(8.4 \%)$. SD, standard deviation; STF, stent treatment failure; PS, predictive score.

and stent type, diameter, length, or any of the predictors from the multivariate analysis.

A younger age and male gender showed higher hazard ratios for STF with no statistical interaction between age and gender. Referral bias for repeat angiography might to some extent explain this observation, but definite or probable stent thrombosis was also more frequent with younger age and male gender. Furthermore, those aged $\leq 50$ years had a significantly higher risk $(p=0.009)$ of STF than those between 51 and 60 years with a similar allcause mortality. For the older groups, the competing risk of death may influence the Kaplan-Meier/Cox regression estimate for STF if the survivors have a lower risk of STF than those who died. For these reasons, we chose not to include age and sex in the calculation of the PS. With age and gender set to mean values and all other predictors from the multivariate model (Table 3 ) set to best case $(\mathrm{PS}=1$ : stent diameter $\geq 3.5 \mathrm{~mm}$, stent length $<20 \mathrm{~mm}$, absence of diabetes, chronic occlusion, bifurcation, restenosis, and prior revascularization), the baseline hazard for STF at 10 years was calculated to $8.4 \%$. We found a clear positive association between PS and the risk of STF and a good agreement between the observed and the expected STF rates (Table 4). These observations were consistent for the first as well as for the second half included, as shown in online suppl. Table S7, that may be regarded as a quasi-development and evaluation strategy for the model.

Table 5 shows the number of observed and expected STF in patients treated for one or multiple lesions. The ratios between the multiple- and single-lesion groups of the 
Table 5. Observed and expected stent treatment failures in patients treated for one or multiple lesions

\begin{tabular}{lcc}
\hline & Single-lesion group & Multiple-lesion group \\
\hline Patients, $n$ & 1,473 & 600 \\
Lesions, $n$ & 1,473 & 1,376 \\
Mean number of lesions pr. patient & 1 & 2.3 \\
Observed total number STF, $n$ & 222 & 208 \\
Observed number of STF per lesion, $n / N(\%)$ & $222 / 1,473(16.7)$ & $208 / 1,376(16.6)$ \\
Observed STF per patient, $n / N(\%)$ & $222 / 1,473(16.7)$ & $153 / 600(28.9)^{*}$ \\
Observed total STF per patient, $n / N$ & $222 / 1,473$ & $208 / 600^{\dagger}$ \\
Calculated mean PS for STF per lesion & 2.03 & 2.13 \\
Calculated mean PS for STF per patient & 2.03 & $4.87^{\dagger \dagger}$ \\
\hline
\end{tabular}

PS, predictive score; STF, stent treatment failure. ${ }^{*}$ Some patients had $>1$ STF. ${ }^{\dagger}$ Ratio 2.3 multiple versus single lesion group. ${ }^{\dagger \dagger}$ Ratio 2.4 multiple versus single lesion group.

mean number of lesions treated, the total number of observed STF per patient, and the calculated PSs per patient are similar $(2.3,2.3$, and 2.4 , respectively). This observation indicates that the risk of STF is incrementally increased with each lesion treated. Thus, at the patient level, the sum of the PS for each stented lesions should be used.

\section{Discussion}

In this study, we describe stent-related adverse events occurring up to 10 years after implantation of first-generation DES and examine predictors of outcomes both related to patient, lesion, and stent characteristics. Our main findings are as follows: (1) a smaller stent diameter and a longer stent length show significant and clinically important association with the 10 years' risk of STF and TLF; (2) we determined the stent size and a few lesion and patient characteristics as predictors of STF and quantitated the absolute and relative importance of these predictors for the 10-year risk of STF; (3) the 10-year risk of STF can be estimated from the hazard ratios of the predictors present in a lesion and a PS can be calculated for each lesion; (4) the rate of 10-year STF shows a large individual variation depending on the presence of the predictors of STF varying from around $10 \%$ for lesions treated with stents $\geq 3.0 \mathrm{~mm}$ in diameter and $\leq 30 \mathrm{~mm}$ total stent length or a low PS to nearly $40 \%$ for those with the highest PS; and (5) when $>1$ lesion is treated, the hazard for STF based on the predictors increases incrementally with each lesion. When interpreting the impact of stent size on clinical outcome, it should be considered that the stent size is closely correlated to vessel diameter and lesion length or diffuse disease and in a few cases may express undersizing or complications. However, stent diameter and length are easy to interpret and indisputable objective, unique, and reproducible parameters. Furthermore, stent diameter and length were stronger predictors of outcome than those outlined in the ACC and SCAI lesion classifications based on our multivariate analysis.

The negative impact of diabetes, treatment of restenotic, bifurcation, and chronically occluded lesions, in addition to small diameter and long stent length (vessels and lesions) on outcomes in patients treated with both first- and latergeneration DES, has been described previously $[4,5,10$ 16]. In the present study, we extend these observations for first-generation stents to 10 years and we quantitate the relative and absolute importance of the predictors of outcome.

The 10-year outcomes for first- and second-generation DES have previously been reported for patient- and device-oriented endpoints $[1-4,6]$ with data that generally reflect outcomes for the average patient, lesion, and stent size. Calculation of a PS as we provide here may be used to predict the individual lesion and patient risk and be used for shared decision-making strategies in preference to using knowledge of the average outcome after coronary stenting.

How do our results translate into the current era of later-generation DES? An inherent limitation to very longterm follow-up studies is that stent and PCI technology as well as procedural and drug regimens often will improve through 10 years. Therefore, to inform patients on their very long-term outcomes, sound extrapolation is usually necessary. Clinicians face and tackle this issue everyday making guideline-directed decisions according to SYNTAX and FAME studies $[17,18]$. First, our results may be important for the millions of persons who carry a firstgeneration DES as we find that large subsets of lesions 
have a good 10-year outcome with stent patency (lack of STF) close to $90 \%$. Second, it must be acknowledged and emphasized that the DES type has a much smaller impact on stent-related adverse outcomes than stent size and patient and lesion characteristics. In randomized comparisons, several newer generation stents have performed better than first-generation stents for TLF and TLR at 5-10 years with HRs of $0.75-0.90[3,5,10,19,20]$. However, this $10-25 \%$ relative difference between first- and latergeneration stents is far smaller than the several hundred percent variations for the risk of STF between high- and low-risk lesions in our study-and also far smaller than the variation ( $>100 \%$ already at 2 years) in stent thrombosis and TLR reported for the same type of newer generation DES in different all-comer studies [4]. A recent expert consensus document reported a $10 \%$ TLR rate 5 years after treatment with newer generation thin or ultrathin strut DES [4]. However, this 10\% TLR rate is patient oriented. The lesion-oriented TLR seems closer to 7\%. But still these $7-10 \%$ are higher than the 5-year TLR rate for the large group of lesions treated with $\mathrm{a} \geq 3.0$ and $\leq 30 \mathrm{~mm}$ firstgeneration DES (5.7\%) or a lesion with PS $<1.5$ (5.6\%) in the present study. Such observations emphasize the importance of performing individual estimates for the risk of stent treatment failure. Until similar analyses of 10 -year outcome predictors as those provided in the present study become available for newer generation stents, stents which by then may be outdated, it may be justified to estimate the risk of STF with contemporary generation stents by assuming a $10-25 \%$ lower baseline hazard $[3,5,10,19,20]$. Indeed for lesions with a PS $\leq 1.5$, we can safely inform our contemporary patients treated with newer DES of a $90 \%$ or better patency rate (free of STF) at 10 years.

Further limitations are that intravascular pressure recordings and imaging were not routinely used, and postdilatation of stents was not mandatory during the period of the present study, all factors that may improve the outcomes [21]. Use of intracoronary imaging would also provide the real diameter of the implanted stent instead of the nominal diameter as was used in our study. Also we did not have scheduled information on kidney function, another known predictor of long-term outcome [14], and that information of the left ventricular function was not available in the study database. However, a history of a previous myocardial infarction that may serve as a surrogate of a reduced left ventricular function was not a predictor of STF, only of major adverse cardiac events and cardiac death as we previously reported [8].

In conclusion, in patients treated with PCI, the 10-year rate of stent-related adverse outcomes shows large varia- tions depending on the presence of risk factors. Large subsets of lesions treated with first-generation DES have a favorable 10-year outcome. The risk of stent treatment failure may be estimated from the stent size and a few patient and lesion characteristics. In preference to using knowledge about the average outcome after implantation of a particular coronary DES, knowledge and use of our data may be used to improve estimates of the long-term risk of stent treatment failure in individual lesions and patients and thereby be an aid in tailoring shared decisions. Our data may represent an important point of reference for future studies with newer generation DES.

\section{Acknowledgments}

The SORT-OUT II study group.

\section{Statement of Ethics}

The study was approved by the Copenhagen County Ethics Committee (KA04085), and all patients gave written informed consent.

\section{Conflict of Interest Statement}

The authors have no conflict of interest to declare.

\section{Funding Sources}

Boston Scientific and Cordis, Johnson and Johnson Company, both donated unrestricted grants to conduct the study at the departments involved. These companies had no role in the design and conduct of the study; the collection, management, analysis, or interpretation of data; or the preparation, review, and approval of the manuscript.

\section{Author Contributions}

Lars Kjøller-Hansen and Anders Michael Galløe: conceptualization, methodology, formal analysis, and investigation writing draft and editing. Henning Kelbæk, Evald Høj Christiansen, Peter Riis Hansen, Thomas Engstrøm, Anders Junker, Niels Bligaard, and Jørgen Lykke Jeppesen: conceptualization, writing review.

\section{Availability of Data and Material}

Data are not publicly available. Enquiries can be directed to the corresponding author. 


\section{References}

1 Galløe AM, Kelbæk H, Thuesen L, Hansen HS, Ravkilde J, Hansen PR, et al. 10-year clinical outcome after randomization to treatment by sirolimus- or paclitaxel-eluting coronary stents. J Am Coll Cardiol. 2017;69:61624.

2 Yamaji K, Räber L, Zanchin T, Spitzer E, Zanchin C, Pilgrim T, et al. Ten-year clinical outcomes of first-generation drug-eluting stents: the sirolimus-eluting vs. paclitaxeleluting stents for coronary revascularization (SIRTAX) VERY LATE trial. Eur Heart J. 2016;37(45):3386-95.

3 Kufner S, Joner M, Thannheimer A, Hoppmann P, Ibrahim T, Mayer K, et al. Tenyear clinical outcomes from a trial of three limus-eluting stents with different polymer coatings in patients with coronary artery disease. Circulation. 2019;139(3):325-33.

4 Stefanini GG, Alfonso F, Barbato E, Byrne RA, Capodanno D, Colleran R, et al. Management of myocardial revascularisation failure: an expert consensus document of the EAPCI. EuroIntervention. 2020;16(11):e875-90.

5 Madhavan MV, Kirtane AJ, Redfors B, Généreux $\mathrm{P}$, Ben-Yehuda $\mathrm{O}$, Palmerini T, et al. Stent-related adverse events $>1$ year after percutaneous coronary intervention. J Am Coll Cardiol. 2020;75(6):590-604.

6 Pareek M, Madsen M, Warnakula Olesen KK, Okkels Jensen L, Høj Christiansen E, Dalby Kristensen S, et al. Ten-year outcomes from a randomised comparison of zotarolimus-eluting and sirolimus-eluting stents: the SORT OUT III study. EuroIntervention. 2019; 15(11):e1022-4.

7 Galløe AM, Thuesen L, Kelbaek H, Thayssen P, Rasmussen K, Hansen PR, et al. Comparison of paclitaxel- and sirolimus-eluting stents in everyday clinical practice. The SORT OUT II randomized trial. JAMA. 2008;299:409-16.

8 Kjøller-Hansen L, Bligaard N, Kelbæk H, Christiansen EH, Thuesen L, Hansen PR, et al. Ten-year clinical outcome of patients treated with a drug-eluting stent in the proximal left anterior descending artery segment compared with patients stented in other non-left main coronary segments. EuroIntervention. 2018;14:764-71.
9 Cutlip DE, Windecker S, Mehran R, Boam A, Cohen DJ, van Es GA, et al. Clinical end points in coronary stent trials: a case for standardized definitions. Circulation. 2007; 115(17):2344-51.

10 Serruys PW, Farooq V, Kalesan B, de Vries T, Buszman P, Linke A, et al. Improved safety and reduction in stent thrombosis associated with biodegradable polymer-based biolimuseluting stents versus durable polymer-based sirolimus-eluting stents in patients with coronary artery disease: final 5-year report of the LEADERS (Limus Eluted From A Durable Versus ERodable Stent Coating) randomized, noninferiority trial. JACC Cardiovasc Interv. 2013;6(8):777-89.

11 Hsieh IC, Hsieh MJ, Chang SH, Wang CY, Lee $\mathrm{CH}$, Yang $\mathrm{CH}$, et al. Vessel size and longterm outcomes after limus-based drug-eluting stent implantation focusing on mediumand small-diameter vessels. Angiology. 2017; 68(6):535-41.

12 Lee CH, Kang DY, Han M, Hur SH, Rha SW, Her SH, et al. Differential cut-off points and clinical impact of stent parameters of various drug-eluting stents for predicting major adverse clinical events: an individual patient data pooled analysis of seven stent-specific registries and 17,068 patients. Int J Cardiol. 2019;282:17-23.

13 Buiten RA, Ploumen EH, Zocca P, Doggen CJM, van der Heijden LC, Kok MM, et al. Outcomes in patients treated with thin-strut, very thin-strut, or ultrathin-strut drug-eluting stents in small coronary vessels: a prespecified analysis of the randomized BIO-RESORT trial. JAMA Cardiol. 2019;4(7):659-69.

14 Miura K, Kadota K, Habara S, Miyawaki H, Shimada T, Ohya M, et al. Ten-year clinical outcomes after sirolimus-eluting stent implantation: impact of an in-stent restenosis target lesion. Am Heart J. 2016;175:47-55.
15 Grundeken MJ, Wykrzykowska JJ, Ishibashi Y, Garg S, de Vries T, Garcia-Garcia HM, et al. First generation versus second generation drug-eluting stents for the treatment of bifurcations: 5-year follow-up of the LEADERS allcomers randomized trial. Catheter Cardiovasc Interv. 2016;87(7):E248-60.

16 Lefèvre T, Haude M, Neumann FJ, Stangl K, Skurk C, Slagboom T, et al. Comparison of a novel biodegradable polymer sirolimus-eluting stent with a durable polymer everolimuseluting stent: 5-year outcomes of the randomized BIOFLOW-II trial. JACC Cardiovasc Interv. 2018;11(10):995-1002.

17 Thuijs DJFM, Kappetein AP, Serruys PW, Mohr FW, Morice MC, Mack MJ, et al. Percutaneous coronary intervention versus coronary artery bypass grafting in patients with three-vessel or left main coronary artery disease: 10-year follow-up of the multicentre randomised controlled SYNTAX trial. Lancet. 2019;394:1324-34.

18 Tonino PA, De Bruyne B, Pijls NH, Siebert U, Ikeno F, van' t Veer M, et al. Fractional flow reserve versus angiography for guiding percutaneous coronary intervention. N Engl J Med. 2009;360(3):213-24.

19 Jensen LO, Thayssen P, Christiansen EH, Maeng M, Ravkilde J, Hansen KN, et al. Safety and efficacy of everolimus- versus sirolimus-eluting stents: 5-year results from SORT OUT IV. J Am Coll Cardiol. 2016;67(7):75162.

20 Shiomi H, Kozuma K, Morimoto T, Kadota K, Tanabe K, Morino Y, et al. 7-year outcomes of a randomized trial comparing the first-generation sirolimus-eluting stent versus the newgeneration everolimus-eluting stent: the RESET trial. J Am Coll Cardiol Intv. 2019;12: 637-47.

21 Serruys PW, Kogame N, Katagiri Y, Modolo R, Buszman PE, Íñiguez-Romo A, et al. Clinical outcomes of state-of-the-art percutaneous coronary revascularisation in patients with three-vessel disease: two-year follow-up of the SYNTAX II study. EuroIntervention. 2019;15(3):e244-52. 